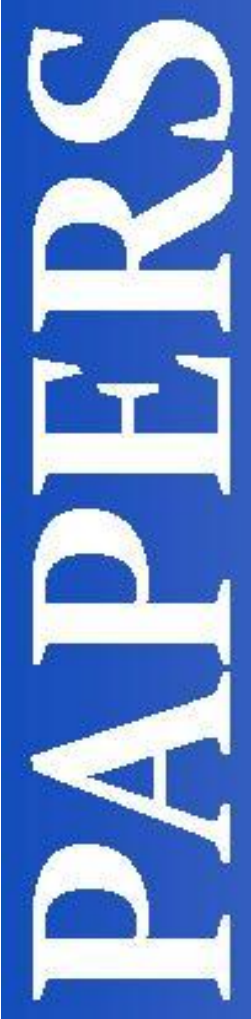

Investment Incentives under Emission Trading: An Experimental Study
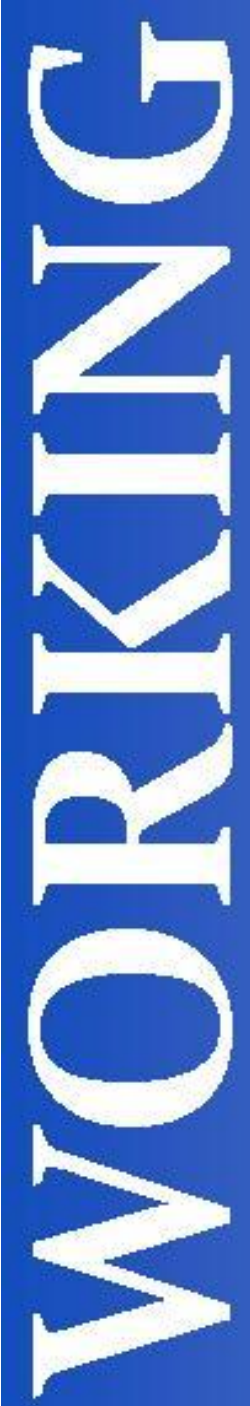

Castellón (Spain) 


\title{
Investment Incentives under Emission Trading: An Experimental Study
}

\author{
Eva Camacho-Cuena \\ Universitat Jaume I \\ LEE \& Economics Department \\ camacho@eco.uji.es
}

\author{
Till Requate \\ University of Kiel \\ Economics Department \\ requate@economics.uni-kiel.de
}

\author{
Israel Waichman \\ University of Heidelberg \\ Department of Economics \\ waichman@eco.uni-heidelberg.de
}

$2012 / 22$

\begin{abstract}
This paper presents the results of an experimental investigation on incentives to adopt advanced abatement technology under emissions trading. Our experimental design mimics an industry with small asymmetric polluting firms regulated by different schemes of tradable permits. We consider three allocation/auction policies: auctioning off (costly) permits through an ascending clock auction, grandfathering permits with re-allocation through a single-unit double auction, and grandfathering with reallocation through an ascending clock auction. Our results confirm both dynamic and static theoretical equivalence of auctioning and grandfathering. We nevertheless find that although the market institution used to reallocate permits does not impact the dynamic efficiency from investment, it affects the static efficiency from permit trading.
\end{abstract}

Keywords: C92, D44, L51, Q28, Q55

JEL Classification: Environmental policy, abatement technology, taxes, permit trading, auctions opportunity, Ultimatum Game. 


\title{
Investment Incentives under Emission Trading: An Experimental Study
}

\author{
Eva Camacho-Cuena* $\quad$ Till Requate ${ }^{\dagger} \quad$ Israel Waichman ${ }^{\ddagger}$
}

This version: March 21, 2012

\begin{abstract}
This paper presents the results of an experimental investigation on incentives to adopt advanced abatement technology under emissions trading. Our experimental design mimics an industry with small asymmetric polluting firms regulated by different schemes of tradable permits. We consider three allocation/auction policies: auctioning off (costly) permits through an ascending clock auction, grandfathering permits with re-allocation through a single-unit double auction, and grandfathering with reallocation through an ascending clock auction. Our results confirm both dynamic and static theoretical equivalence of auctioning and grandfathering. We nevertheless find that although the market institution used to reallocate permits does not impact the dynamic efficiency from investment, it affects the static efficiency from permit trading.
\end{abstract}

JEL Classification: C92; D44; L51; Q28; Q55

Keywords: environmental policy; abatement technology; taxes; permit trading; auctions

\footnotetext{
${ }^{*}$ Department of Economics, University Jaume I of Castellón, 12071 Castellón, Spain. Email: camacho@eco.uji.es

${ }^{\dagger}$ Department of Economics, University of Kiel, Olshausenstrasse 40, 24118, and Institute of World Economics, 24105, Kiel, Germany. Germany. Email: requate@economics.uni-kiel.de

${ }^{\ddagger}$ Corresponding author. Department of Economics, University of Heidelberg, Bergheimstrasse 20, 60115, Heidelberg, Germany. Email: waichman@eco.uni-heidelberg.de
} 


\section{Introduction}

It is widely acknowledged today that 'market-based' pollution control instruments, such as emission taxes and tradable permits, are powerful and efficient tools for curbing pollution. At an early stage, Kneese and Schultze (1975) emphasized that one of the most important criteria for judging different pollution control policies is the extent to which these policies encourage firms to develop or adopt low-pollution technologies. Since then a large body of both theoretical and empirical research has analyzed the impact of different policy instruments on both technological change and the diffusion of new technologies.

The first attempts to rank environmental policy instruments were made by Downing and White (1986), Malueg (1989), Milliman and Prince (1989), and Jung et al (1996). ${ }^{1}$ Taking aggregate cost savings as the ranking criterion for pollution control policies, these studies, however, ignore the individual firms' incentives to adopt new technologies. Later, Kennedy and Laplante (2000) and Requate and Unold (2003, 2001) (for the case of adoption of new technology), and Montero (2002a,b) and Fischer et al (2003) (for the case of technology innovation) argue that incentives provided by policy instruments to adopt (or develop) new technologies in equilibrium have to be considered in evaluating different pollution control policies. In other words, the number of firms that adopt the new technology in equilibrium should be determined endogenously. In particular, Requate and Unold (2003, 2001) study the incentives provided by emission taxes and tradable permits to adopt a given low-pollution technology. The authors show that if the regulator is well informed about the new technology ${ }^{2}$ and firms are asymmetric, both instruments provide efficient incentives to invest in advanced abatement technology if the regulator levies a tax rate at the Pigouvian level or the equivalent emission cap, respectively. If firms are symmetric, however, Requate and Unold (2003) show that an ex ante setting of emission tax rates will fail to induce the first-best investment pattern. Although permits may theoretically lead to first-best investment, firms face a coordination problem that may prevent them 
from pursuing this course. Moreover, for both, symmetric and asymmetric firms, the authors establish the equivalence of grandfathered and auctioned permits with respect to technology adoption.

In this paper we study investment incentives from an experimental perspective. To this end we have conducted a series of economic experiments to simulate investment in a low-pollution technology when firms are regulated by emission permit markets. In particular, we investigate the impact of different allocations of property rights (free vs. costly allocation of permits) and different auction schemes on the efficiency of technology adoption. ${ }^{3}$ In a nutshell, our experimental design is as follows: After subjects (firms) are assigned their initial technologies, they decide whether or not to adopt a new technology that lowers their marginal abatement cost schedules. In a second phase they participate in a permit auction. The main research question is whether or not this two-step procedure induces i) an optimal allocation of investment decisions and ii) an efficient allocation of permits after the investment phase. Since symmetric firms face a coordination problem with respect to which firm will invest (Requate and Unold, 2003), we follow the asymmetric model of Requate and Unold (2001) by allocating different initial technologies to the firms, whereas the new technology is the same for all firms.

Furthermore, we have to specify the mechanisms for auctioning and re-allocating permits. In the theoretical literature these mechanisms are usually modeled as a black box. With the exception of Montero (2002a,b), firms are mostly assumed to behave as price-takers, and the auction clears the market. In a set-up with grandfathering, it is natural to choose a double auction for re-allocating the permits among the firms. Under costly allocation (so-called auctioning) we decided to implement an ascending clock auction. In addition, we conduct a third treatment where permits are grandfathered and then re-allocated through a (double) ascending clock auction.

Our main results are as follows. First, we find that in all three treatments the observed investment patterns are relatively close to the theoretical first-best allocation. 
Second, concerning investment efficiency, none of the three mechanisms outperforms any of the other two. Third, we find that the individual investment decision is mainly determined by the initial technology.

In the permit trading phase we observe that in all treatments prices are higher and net trade volumes are lower than predicted by the theoretical equilibrium. In the treatment with grandfathering and double auction we observe speculative trade, that is, some subjects buy and sell permits within the same trading round. This is surprizing since our design does not provide any reason to engage in arbitrage. Finally, we find that when permits are allocated for free, the double auction market institution outperforms the ascending clock auction regarding efficient allocation of permits. However, we do not observe any substantial differences between the policy instruments concerning the overall efficiency from both investment and permit trading. These results establish both the dynamic and static equivalence of so-called auctioned and free permit schemes (Requate and Unold, 2003, 2001).

Our paper is organized as follows: The next section reviews the related literature. Section 3 outlines the underlying theoretical model. Section 4 describes the experimental design and procedure, and section 5 sets out the results. Section 6 concludes.

\section{Related Experimental Literature}

Since Plott's (1983) first laboratory experiment on emissions trading, numerous experiments have been conducted on permit trading. ${ }^{4}$ However, only a minority of them consider investment in low-pollution technology when firms participate in emission permit markets.

Ben-David et al (1999) consider an emission permit market where firms produce a good by using capital and causing emissions. In their setting, firms can use one of three possible production technologies where permits and capital costs are inversely related (i.e. the cleanest technology is the most expensive one in terms of capital). In 
each round the firms can make an irreversible investment decision to become cleaner (but not vice versa). Surprisingly, the authors find that heterogeneity leads to lower efficiency from trade. The intuition behind this result is that heterogeneity increases potential gains from trade, but also creates more noise in the market. As a consequence suboptimal decisions are more costly when markets are more heterogeneous.

Hizen et al (2001) and Kusakawa and Saijo (2003) investigate investment with emissions trading, where trading is either bilateral or takes place using a double auction. These authors find that the irreversibility of investment and a time-lag in abatement reduce efficiency. Buckley et al $(2005,2006)$ compare between implementation of cap-and-trade and baseline-and-credit (with and without varying production capacity) where emission rate is endogenously determined by the subjects. The authors find, in line with theory, that baseline-and-credit scheme results in higher aggregate output and emissions.

Finally, Gangadharan et al (forthcoming) examine the interaction between permit banking and (irreversible) investment in a cleaner technology. The authors consider an industry with asymmetric firms that differ with respect to production capacity and cleanliness. Permits are allocated for free and can be traded through a double auction. As in our model, the effect of investment in cleaner technology is asymmetric (dirty firms gain more by investing). In contrast to our design, information about investment is made public and given to all participants. The authors find that firms tend to over-invest and over-bank. Accordingly, the result is sub-optimal market performance.

Overall, the experimental evidence on efficiency of investment decisions is mixed. There are few experimental studies considering explicit investment decisions of regulated firms in low-pollution technologies. In particular there is no systematic study on how the insitutional design of emissions trading (free vs. costly allocation of permits, and the trading mechanism) impacts on pre-investment decisions. Note that our design is closest to that by Gangadharan et al (forthcoming) and thus our findings are, 
to some extent, related to theirs.

\section{Theoretical Background}

This section presents the theoretical model that serves as a basis for our experiment. As mentioned above, our study draws on the models of Requate and Unold (2001, 2003), who establish the dynamic (ax ante and ex post) optimality of tradable emission permits and the equivalence of auctioned permits and grandfathering. ${ }^{5}$

Consider an industry consisting of $n$ polluting firms and $K$ different initial technologies. Each firm $i=\{1, \ldots, n\}$ is endowed with one of these initial technologies and can invest in adopting the advanced technology $a$, the same for all firms. The firms' technologies are represented by their abatement cost functions $C^{i}\left(e_{i}, k\right)$ with $k=1, \ldots, K, a$. For any targeted emission level $e$ we assume $C^{i}(e, k)>0$ for $e<\bar{e}_{k}$, where $\bar{e}_{k}$ is the baseline emission level of technology $k=1, \ldots, K$, chosen in the absence of regulation. We denote this by $E M A X$. Investment in advanced abatement technology leads to lower marginal abatement costs, i.e. $-C_{e}^{i}(e, k)>-C_{e}^{i}(e, a)$ for all $e \leq \bar{e}_{k}$, where $-C_{e}^{i}(e, k) \equiv-\partial C^{i}(e, k) / \partial e$ is the marginal abatement cost, written for short as $M A C$. Denoting $k(i)$ as the technology initially owned by firm $i$, we assume without loss of generality that the firms' abatement cost functions are ordered from the dirtiest to the least dirty, i.e. $C^{i}(e, k(i)) \geq C^{i+1}(e, k(i+1))$ and $-C_{e}^{i}(e, k(i)) \geq$ $-C_{e}^{i+1}(e, k(i+1))$. Installing the new technology causes a fixed cost $F>0$, the same for all firms. Moreover, when setting the optimal policy, the regulator uses an increasing and convex social damage function, $D(E)$, that evaluates emissions in monetary terms. Here $E=\sum_{i=1}^{n} e_{i}$ denotes aggregate emissions.

A social planner minimizes total social costs with respect to emissions and the number of firms. When the fixed investment cost is independent of the initial technology, and if not all firms are supposed to adopt in equilibrium the advanced technology, it is always optimal for at least those firms with the highest abatement costs to invest, 
i.e. there will be some index $j$ such that the firms $i=1, \ldots, j$ will invest. Exploiting the fact that $C^{i}\left(e_{i}, a\right)=C^{j}\left(e_{j}, a\right)$ and $e_{i}=e_{j}$ for all $i \leq j$, the social planner's problem can therefore be written as

$$
\min _{\left\{j, e_{a}, e_{j+1}, \ldots, e_{n}\right\}}\left\{j\left[C^{j}\left(e_{a}, a\right)+F\right]+\sum_{i=j+1}^{n} C^{i}\left(e_{i}, k(i)\right)+D(E)\right\}
$$

where $E=j e_{j}+\sum_{i=j+1}^{n} e_{i}$. Clearly for $i>j, e_{i}$ depends solely on the type of technology $k$.

Using $A M A C^{*}(E, j)$ to denote the optimal aggregate marginal abatement cost when the first $j$ firms have adopted the advanced abatement technology, the regulator will choose the optimal aggregate emission level $E^{*}$, satisfying

$$
D^{\prime}\left(E^{*}\right)=A M A C^{*}\left(E^{*}, j\right)
$$

Assuming that a regulating authority uses tradable permits to control emissions, it will issue a number of permits, $L=E^{*}$, to enforce the aggregate emission level $E^{*}$. Using $\sigma$ to denote the market price for permits, firm $i$ with technology $k$ will choose an emission level $e_{i}(\sigma, k)$ such that its marginal abatement cost equals the price of permits: $-C_{e}^{i}\left(e_{i}(\sigma, k), k(i)\right)=\sigma$.

Now, a firm $i$ with original technology $k=1, \ldots, K$ has an incentive to adopt the advanced technology $a$ if and only if

$$
C^{i}\left(e_{i}(\sigma, a), a\right)+F+\sigma\left[e_{i}(\sigma, a)-\hat{e}_{i}\right]<C^{i}\left(e_{i}(\sigma, k), k\right)+\sigma\left[e_{i}(\sigma, k)-\hat{e}_{i}\right],
$$

where $\hat{e}_{i}$ is firm $i$ 's initial endowment of permits (if any). Condition (2) indicates that investment will be profitable if the total cost (made up of abatement cost, expenditures on permits, and investment cost) is lower than the abatement cost plus expenditures for permits without investment. This condition crucially depends on the permit price and hence on the total supply of permits $L$ chosen by the regula- 
tor. Even if firms are identical, it may be the case that in equilibrium some firms will adopt the new technology and some will not (see Requate and Unold, 2003). In fact, the price of permits and the number of firms are both determined endogenously. Note that, in general, multiple equilibria are possible in the investment stage. In a symmetric setting, equilibria are unique up to permutations of the players that either do or do not invest. In asymmetric settings, by contrast, depending on parameters efficient and inefficient equilibria may occur. In our experimental setting, however, we chose parameters such that the investment equilibrium is unique. Requate and Unold show that socially optimal allocation can be theoretically implemented by issuing the ex-ante socially optimal number of emission permits for both a completely symmetric model (Requate and Unold, 2003) and an asymmetric model (Requate and Unold, 2001). In our experimental study, we therefore assume that the regulator issues the optimal number of permits. Requate and Unold $(2001,2003)$ also show that the social optimum can be decentralized, irrespective of whether permits are allocated for free (grandfathered) or are auctioned off. The type of auction or trading procedure under grandfathering are not specified in these papers. They merely assume that the permit market will always clear.

\section{Experimental Design}

The experiment was conducted in the experimental laboratory of the University of Kiel using the z-Tree experimental software (Fischbacher, 2007). Subjects were volunteer students with at least a Bachelor's degree in Economics. Earnings during the experiments were designated in Experimental Currency Units (ECUs) and converted into Euros at the end of the session. In the following sections we describe the treatments as well as the experimental procedure implemented. 


\subsection{Parameters and treatments}

We chose five different technologies $T_{1}, \ldots, T_{5}$. Technology $T_{1}$ (technology $T_{5}$ ) implies the highest (lowest) marginal abatement cost (MAC) and the highest (lowest) business-as-usual emission level (EMAX). The firms' technologies are represented by stepwise, downward sloping marginal abatement cost functions depicted in Table 1. If there is no pollution control and the firms do not make any abatement effort, their default profit is $\Pi^{0}=1200$ ECU. The regulator issues a number of permits $L=108$ (110) in case of grandfathering (auctioning). ${ }^{6}$

By investing a fixed amount of $F=580$ ECU, any subject (firm) can adopt the new technology $a$, which has considerably lower levels of MAC and EMAX than even the most efficient initial technology.

- Table 1 around here -

With these parameters, only the firms with technologies $T_{1}$ and $T_{2}$ should invest in a socially optimal allocation. This is also an equilibrium with a theoretical equilibrium price of 60 ECU. ${ }^{7}$ Note that due to the choice of our parameters, the efficient allocation is the only equilibrium.

- Figure 1 around here -

We conducted three different treatments implementing the following policy instruments:

- Auctioning-off permits through an ascending clock auction (AAC). We refer to this mechanism as pure auctioning.

- Grandfathering and re-allocating permits through a single-unit double auction (GDA) 
- Grandfathering and re-allocating permits through an ascending (double) clock auction (GAC)

Typically, under a system of grandfathering (i.e. free allocation of permits), subjects can bilaterally trade the permits. To mimic this, it is natural to choose a single-unit double auction. ${ }^{8}$ For costly allocation of permits (so-called auctioning), several designs might potentially be selected. We chose an ascending clock auction because it is simple to implement and to understand. ${ }^{9}$

Since the first two treatments (grandfathering with double auction and auctioning with ascending clock auction) differ with respect to two design features (free vs. costly allocation; double auction vs. ascending clock auction), it would not have been possible to assign differences in performance either for different allocation schemes or to different trading procedures. We therefore also conducted treatment GAC where permits were allocated for free and re-allocated via an ascending clock auction.

Because of the relative complexity of the experiment we decided to use economic framing because this helps to increase the transparency and clarity of the task. Related to this issue Loewenstein (1999, p.30) claims that "context-free [abstract framing] provides the same amount of context, albeit somewhat more alien, as any other environment".

\subsection{Experimental procedure}

We have conducted three sessions for each treatment. A group of 18 subjects participated in each session, mimicking polluting firms that are subject to regulation. ${ }^{10}$ Upon arrival at the laboratory, subjects were randomly assigned to one of the computer terminals. Instructions were then distributed and subjects' questions were answered before subjects had participated in the two-part experiment. ${ }^{11}$ In the first part, four rounds of a tax treatment were conducted. ${ }^{12}$ The purpose of this first part of the session was to make the subjects familiar with the pure investment decision without facing the strategic uncertainty induced by the auction, notably regarding 
the permit price. The design and the results of the tax treatments are shown in Appendix A. In the second part of the session subjects participated in one of three different treatments AAC, GDA, or GAC, to be precisely described below. In this second part subjects played six rounds of a one-shot game. ${ }^{13}$ Each round consisted of the following three stages:

Stage 1: Technology assignment and initial permit allocation Each subject is randomly assigned an initial technology $k=T_{1}, \ldots, T_{5}$, where four subjects each are endowed with technologies $T_{1}, T_{3}$, and $T_{5}$ and three subjects each with technologies $T_{2}$ and $T_{4}$. Moreover, in these treatments with grandfathering, i.e. GDA and GAC, permits are allocated depending on the firms' initial technology as displayed in Table 2. Both the initial distribution of technologies and the criteria for permit allocation is common knowledge to the subjects.

- Table 2 around here -

Stage 2: Investment decision Subjects simultaneously decide whether to keep the initial technology $k=T_{1}, \ldots, T_{5}$ or to adopt the new technology $a$, paying the corresponding investment cost $F=580$.

Stage 3: Permit auctioning Subjects participate in a permit auction (full compliance with the regulation was imposed and banking of permits was not allowed). The total number of auctioned (allocated) permits is fixed and known to the subjects during the experiment. Subjects are not allowed to buy more permits than their current maximum emission level. In addition, in the treatments where permits are grandfathered no short-selling is feasible.

At the end of the session the subjects' final payoff was computed by randomly choosing one round from the first part (tax treatment) and one round from the second 
part (permit treatment). Each session lasted approximately 2.5 hours and the average payoff was around $€ 35$.

In the following we introduce the details of the implemented permit trading treatments:

In the GDA treatment a single-unit double auction is implemented. The permit market opens for three minutes for subjects to buy and/or sell permits. This they can do either by submitting bid(s) or offer(s), or by accepting standing bid(s) or offer(s). Every transaction refers only to one permit. Once the market is closed, the profit for firm $i$ in round $t$ is given by

$$
\Pi_{i, t}= \begin{cases}\Pi^{0}-C^{i}\left(e_{i, t}, a\right)-x-F & \text { if the firm invests in round } t \\ \Pi^{0}-C^{i}\left(e_{i, t}, k\right)-x & \text { if it does not invest in round } t\end{cases}
$$

where $k \in\left\{T_{1}, \ldots, T_{5}\right\}$ denotes the index of the abatement technology, and $x$ is defined as $x=\sum_{j=1}^{J} \sigma_{i, j, t} Z_{i, j, t}$. Moreover, $J$ is the number of trades, $\sigma_{i, j, t}$ is the price that subject $i$ pays or receives in trade $j$, and $Z_{i, j, t} \in\{1,-1\}$ indicates whether he/she buys $\left(Z_{i, j, t}=1\right)$ or sells $\left(Z_{i, j, t}=-1\right)$ a permit. Net trades sum up to $\sum_{j=1}^{J} Z_{i, j, t}=e_{i, t}-\hat{e}_{i}$ where $\hat{e}_{i}$ is subject $i^{\prime} s$ initial endowment of permits.

In the $A A C$ treatment, permits are auctioned off through an ascending clock auction. In this procedure the initial price is set at 5 ECU. Subjects then have 40 seconds to place their demand for permits (their requested number of permits) at that price. ${ }^{14}$ If aggregate permit demand exceeds supply set by the regulator (108 permits), the price is increased by $10 \mathrm{ECU}$ (so that the next price is $15 \mathrm{ECU}$, then $25 \mathrm{ECU}$, and so on). ${ }^{15}$ The auction then continues until the quantity required by the firms is smaller or equal to permit supply. If this is the case, the auction ends and each subject gets its demanded quantity at this last price.

Finally, in the GAC treatment the procedure is similar to the AAC treatment, except that for the given price the subjects now have 40 seconds to place their demand (requested number of permits) or their supply (number of permits they offer). If 
aggregate demand is smaller or equal to aggregate supply, the auction ends and each bidder obtains his/her demanded quantity at this final price. ${ }^{16}$

The profit of firm $i$ in round $t$ for the treatments with ascending clock auction (AAC, GAC) is given by

$$
\Pi_{i, t}= \begin{cases}\Pi^{0}-C^{i}\left(e_{i, t}, a\right)-\sigma\left(e_{i, t}-\hat{e}_{i}\right)-F & \text { if the firm invests in round } t \\ \Pi^{0}-C^{i}\left(e_{i, t}, k\right)-\sigma\left(e_{i, t}-\hat{e}_{i}\right) & \text { if it does not invest in round } t\end{cases}
$$

where $\sigma$ is now the uniform price resulting from the auction.

\subsubsection{Eliciting risk attitudes}

At the end of the session we conducted a test to elicit the subjects' risk attitudes. For this purpose we employed the low-payoff menu of paired lotteries (Holt and Laury, 2002), which ranks risk attitudes on a scale ranging from 1 (high degree of risk-loving) to 10 (high degree of risk-aversion). A measure of 4 denotes risk neutrality. ${ }^{17}$ Appendix B provides a detailed description of the menu. The distribution of the risk attitude measures of our sample (pooled across all treatments) is displayed in Figure 2. The figure shows that most subjects $(60 \%)$ are risk averse, although the most frequent choice ( $28 \%$ of the subjects) is of risk neutrality (a subject is classified risk neutral if it switches to the risky alternative after exactly four consecutive choices). There are only few subjects classified as risk loving (10\% of the choices).

- Figure 2 around here -

\section{Results}

We are particularly interested to see whether there are significant differences in performance between the different treatments regarding (i) optimal investment behavior, 
(ii) efficient allocations of permits (reflected by the total abatement costs given the investment decision), and (iii) minimization of total abatement cost. For most of the analysis, we employ the (two-sided) robust rank-order test (F-P test following Fligner and Policello, 1981) $)^{18}$ to pairwise compare between the three treatments.

\subsection{Investment behavior}

We start by evaluating investment behavior. First we compare the aggregate investment patterns under the different treatments with the theoretical optimum. In a second step, we study what factors drive individual firms' investment behavior.

\subsubsection{Aggregate behavior}

For all three implemented treatments, Figure 3 displays the firms' investment decisions depending on the assigned initial technology.

- Figure 3 around here -

Note that in all treatments most of the firms using technologies $T_{1}$ and $T_{2}$ decide to adopt the low emission technology $a$, whereas the number of investing firms decreases as we move to technologies $T_{3}, T_{4}$ and $T_{5}$, i.e. those with initially lower baseline emissions and lower marginal abatement costs. In fact, although the observed investment pattern is close to the socially optimal allocation (which is also an equilibrium) ${ }^{19}$, we find that for all treatments implemented the observed investment patterns differ significantly (at the $5 \%$ level) ${ }^{20}$ from the first-best investment pattern (where only those firms with technologies $T_{1}$ and $T_{2}$ should invest).

Using an F-P test to compare between the different allocation mechanisms (i.e. comparing the AAC and GAC treatments), we do not observe a significant difference between the two treatments at the $10 \%$ level. Next, we compare the effect of the permit re-allocation mechanism, once permits have been distributed for free among 
the firms. In other words, we compare the GAC and the GDA treatments. Employing the F-P test again, we do not find a significant difference in the subjects' investment behavior at the $10 \%$ level. We summarize our findings as follows.

Result 1a: Initial allocation of permits (auctioning vs. grandfathering) has no significant effect on the pattern of technology adoption.

Result 1b: The market institution used to re-allocate permits within an industry (ascending clock vs. single-unit double auction) has no significant effect on the pattern of technology adoption.

\subsubsection{Individual behavior}

To better understand the factors influencing investment behavior in the different treatments, we estimated a pooled Probit model ${ }^{21}$ with robust standard errors clustered across sessions. As explanatory variables we include dummies for the initial technologies assigned, the average price in the previous round, the risk-attitude measure ranging between 1 (high degree of risk-loving) and 10 (high degree of risk-aversion), and the period number. ${ }^{22}$

- Table 3 around here -

First we study the impact of the initial technology on the probability to invest. Since firms endowed with dirtier technologies gain more from adopting the new technology, we expect the firms' investment probability to decrease when initially being endowed with a cleaner technology. More precisely, we expect discrete jumps in adoption when moving across technologies (particularly between technology $T_{2}$ and $T_{3}$ denoting the borderline between adoption and non-adoption in social optimum). The 
results reported in Table 3 confirm our hypothesis for all treatments implemented. ${ }^{23}$

Secondly, since the permit price observed in the market is the only information the subjects have about previous aggregate investment, it is natural to conjecture that firms will be more likely to invest if they expect high prices in the permit market. Therefore, our hypotheses is that a higher permit price in one round will increase the firms' investment probability in the next round. However, this hypothesis is not confirmed for the grandfathering treatments, and it is only weakly confirmed $(P-$ value $=0.09)$ when permits are initially auctioned off (AAC treatment). One possible explanation for not finding a significant effect of price on investment in the GAC and GDA treatments is that the initial grandfathering allocates permits in a corrective way (i.e. dirtier firms are endowed with more permits). This reduces the dependency of the firms on the auction compared to the situation where firms have to purchase all the permits.

Finally, investment reduces the firm's dependency on the permit price and may thus be perceived as an insurance device against unfavorable scenarios. Thus, we expect risk aversion to influence the firms' investment decisions. We do not observe, however, that the risk attitude influences the investment behavior in the AAC and GDA treatments. Moreover, we even observe that the lower the risk aversion, the higher is the probability to invest when permits are initially grandfathered and relocated through an ascending bid auction (GAC treatment). A possible explanation for the latter result is that investment may be perceived as a risky action itself rather than insurance. This may be particularly true in treatments where "dirtier" firms are compensated by receiving more permits than "cleaner" firms. We can summarize our findings as follows:

Result 2a: The firms' initial technology is the main driver for their investment decisions, and therefore, firms with higher initial marginal abatement costs have a higher probability to adopt the new technology. Moreover, consistent with theory, we 
observe a clear borderline between adoption probabilities of firms with initially dirty technologies $T_{1}$ and $T_{2}$, compared to the firms with cleaner technologies $T_{3}, T_{4}$, and $T_{5}$.

Result 2b: When permits are initially grandfathered and relocated through an ascending clock auction (i.e. under GAC), the investment probability increases as firms are less risk averse.

\subsection{The permit market}

In this section we analyze the different treatments according to prices and trading volume. One important aspect is whether these prices and volumes reflect the firms' investment pattern. Note that in order to evaluate the observed permit prices and volumes, we cannot use the theoretically optimal equilibrium price and volumes computed in section 4 as a benchmark, since that price results from the theoretically optimal investment pattern (if only firms of type $T_{1}$ and $T_{2}$ invest in the advanced technology, we expect an equilibrium permit price equal to 60 ECU (See Figure 1)) and we have already seen that firms do not behave optimally concerning technology adoption. Therefore, we should calculate the theoretical equilibrium prices and trade volumes given the observed investment pattern. We denote these values as expected prices and volumes. Table 4 shows the observed average prices and volumes in the first two columns and the efficient (expected) prices and volumes in the last two columns.

- Table 4 around here -

We see that in all treatments the permit market suffers from over-pricing, that is, the observed prices are higher than the expected price given the observed investment pattern resulting from the first phase of each round. ${ }^{24}$ Looking at the observed trade volumes, we find lower trade volumes than expected in the treatments using the 
ascending-clock auction to allocate (AAC treatment) or rellocate (GAC treatment) permits, whereas an excessive trade volume is observed when trade takes place via the double auction (GDA treatment). However, in this last case it is important to distinguish between the total and the net trade volume. Whereas the net trade volume refers to the permit variation, that is, the difference between the permits held at the beginning and at the end of the auction, the total trade volume refers to the total number of transactions. The difference between net and total volume can be considered as speculative trading, defined as one subject buying and selling permits in the same round in order to gain from price volatility within a given trading period. From Table 5 we observe that speculative trading represents around $27 \%$ of total volume. Indeed, the net volume observed is lower than expected, which is in line with the other two implemented mechanisms. ${ }^{25}$

- Table 5 around here -

We summarize our findings on the permit market performance as follows:

Result 3a: Given the firms' investment pattern all permit trading mechanisms suffer from insufficient (net) trading.

Result 3b: When the double auction mechanism is used to rellocate permits among firms, speculative trading emerges and generates excessive trade volumes in the permit market.

Our finding of speculative trading in the double auction treatment was also found in many other environments, most strikingly in asset markets with common values such as Smith et al (1988) where no trading is expected. Nevertheless, let us take a closer look into speculative behavior. As indicated above, we define a speculator as 
a trader who sells and buys permits within the same round. In this respect we can say that firms tried to engage in arbitrage. In contrast to other financial assets, an emission permit can be considered as a production input. Therefore we would expect that the production technology influences the decision to speculate.

Table 6 summarizes the results of a pooled Probit estimation (with robust standard errors clustered across sessions) looking for factors that influence speculative trading. Interestingly, it is mainly the risk attitude that drives speculation $(P-$ value $=0.00)$ : the lower the degree of risk aversion, the higher the probability to speculate. Moreover, a higher permit price in the previous round is correlated with a higher probability to engage in a speculative action $(P-$ value $=0.02)$. These findings indicate that speculation is not merely an action that is correlated with confusion. By contrast, the initial technology does not have a significant impact on speculative trade. ${ }^{26}$

- Table 6 around here -

Furthermore, it is interesting to observe that speculators did not manage to outperform non-speculators. On average, speculators even earned a lower profit than those who only bought or sold permits. ${ }^{27}$ Our findings give rise to the next results:

Result 3c: The lower is the individual's risk-aversion and the higher the previous round's average permit price the higher the probability that he/she will engage in speculative behavior in the permit market.

Result 3d: On average speculators earn a lower profit than non-speculators.

We do not exactly know why subjects engage in speculative trade. Since less risk averse subjects tend to speculate more, some subjects try to make money by engaging in some kind of gambling. It may also be the case that some subjects have irrational 
expectations on the price dynamics during the double auction. Trying to correct their trading decisions leads to what we observe as speculative trading.

\subsection{Efficiency comparisons}

An important issue, being also of political interest, is to compare the different allocation and trading schemes with respect to efficiency. A typical efficiency measure to test the performance of mechanisms in economic experiments is the ratio of the theoretical minimal social cost divided by the social cost induced by the observed behavior in the experiment. In the mechanisms considered here, two sources for potential inefficiencies occur: suboptimal investment decisions and suboptimal permit allocations through auction or bilateral trade. It is therefore instructive to decompose these two sources for potential inefficiencies.

\subsubsection{Efficiency in the permit market}

We begin by looking at the efficiency of permit allocation. For this purpose, we denote the total variable abatement cost as TVAC, i.e. $T V A C=\sum_{i=1}^{n} C^{i}\left(e_{i}, \kappa(i)\right)$, where $\kappa(i) \in\{k(i), a\}$ is the actual technology used by firm $i$ after the investment decision. Let $\kappa=(\kappa(1), \ldots, \kappa(n))$ be the technology profile after the investment stage. Further $\kappa^{o b s}=\left(\kappa^{o b s}(1), \ldots, \kappa^{o b s}(n)\right)$ is the observed technology profile while $\kappa^{*}=\left(\kappa^{*}(1), \ldots, \kappa^{*}(n)\right)$ is the efficient one. Additionally, we use $e^{o b s}=$ $\left(e_{1}^{o b s}, \ldots, e_{n}^{o b s}\right)$ to denote the observed emission-permit allocation, and $e^{*}(\kappa)$ to denote the optimal emission-permit allocation contingent on a given technology profile $\kappa$. Then $T V A C\left(e^{o b s}, \kappa^{o b s}\right)=\sum_{i=1}^{n} C^{i}\left(e_{i}^{o b s}, \kappa^{o b s}(i)\right)$ is the observed TVAC, while $T V A C\left(e^{*}\left(\kappa^{o b s}\right), \kappa^{o b s}\right)=\sum_{i=1}^{n} C^{i}\left(e_{i}^{*}\left(\kappa^{o b s}\right), \kappa^{o b s}(i)\right)$ is the theoretically minimal TVAC contingent on the observed investment profile $\kappa$.

Permit-market efficiency is now defined by the ratio of the expected TVAC con- 
tingent on the observed investment profile to the observed TVAC, formally:

$$
E R^{\text {Permit }}=\frac{T V A C\left(e^{*}\left(\kappa^{o b s}\right), \kappa^{o b s}\right)}{T V A C\left(e^{o b s}, \kappa^{o b s}\right)}
$$

The permit-market efficiency-ratios resulting from our three allocation mechanisms are displayed in the first row of Table 7 .

- Table 7 around here -

A pairwise application of an F-P-test (comparing average efficiency ratios at the session level for each pair of treatments) shows that the initial allocation does not affect the efficiency of permit allocation and trading. ${ }^{28}$ By contrast, once permits are issued for free, the double auction market institution outperforms the ascending clock auction. ${ }^{29}$ These results provide further evidence for the efficient performance of the double auction in general and in comparison with other trading institutions (e.g., Smith, 1986, Ledyard and Szakaly-Moore, 1994, etc.). We summarize our findings as follows:

Result 4a: Grandfathering with initial allocation of permits proportional to the maximal emission levels (EMAX) does not lead to higher final permit-market efficiency than pure auctioning. By contrast, the double auction trading institution yields higher final permit-market efficiency than the ascending clock auction.

Result 4a establishes the static efficiency of the different trading institutions. In particular, the finding that efficiency is not affected by the initial allocation mechanism (auctioning vs. grandfathering) is in line with theoretical textbook predictions. This result is remarkable in light of other recent findings where free allocation of permits provides different outcomes than costly auctioning (e.g., Goeree et al, 2010, 
Botelho et al, 2011, etc.). In addition, Table 7 indicates that the standard deviation of the efficiency ratio across sessions is very small in the treatments with free permits compared to those with costly allocation. This may be caused by the fact that under grandfathering the final permit allocation is closer to the initial allocation of permits.

\subsubsection{Efficiency of investment}

In a next step we investigate investment efficiency. To separate this from the allocation efficiency, we look at the counter-factual total abatement cost, including investment, that will result if an efficient allocation emerges through permit trading. For this purpose we define: $I=\left(I_{1}, \ldots, I_{n}\right)$ with $I_{i} \in\{0,1\}$ as the investment pattern, where $I_{i}=1$ if subject $i$ invests and $I_{i}=0$, otherwise. Further we write $I^{*}=\left(I_{1}^{*}, \ldots, I_{n}^{*}\right)$ for the optimal investment pattern, and $I^{o b s}=\left(I_{1}^{o b s}, \ldots, I_{n}^{o b s}\right)$ for the observed one. Clearly $I^{*}$ and $I^{o b s}$ induce the corresponding technology profiles $\kappa^{*}$ and $\kappa^{o b s}$. Then we can define efficiency ratio of investment as the ratio between the lowest possible total abatement cost, including investment cost, and the observed total abatement cost, given the counterfactual that emissions are allocated efficiently.

$$
E R^{\text {Invest }}=\frac{T V A C\left(e^{*}\left(\kappa^{*}\right), \kappa^{*}\right)+F_{i=1}^{n} I_{i}^{*}}{T \operatorname{VAC}\left(e^{*}\left(\kappa^{o b s}\right), \kappa^{o b s}\right)+F_{i=1}^{n} I_{i}^{o b s}}
$$

In the second row of Table 7 we see that the investment efficiency ratios are above 90\% in all treatments. A pairwise application of an F-P-test establishes no difference in performance between the three policy instruments. ${ }^{30}$ We summarize our result as follows:

Result 4b: The different policy instruments do not yield different performances with respect to investment efficiency. 


\subsubsection{Overall efficiency}

Finally we look at the total efficiency, measured as the ratio of the lowest possible total abatement cost divided by the observed total abatement cost. ${ }^{31}$

$$
E R^{T o t a l}=\frac{T V A C\left(e^{*}\left(\kappa^{*}\right), \kappa^{*}\right)+F_{i=1}^{n} I_{i}^{*}}{T V A C\left(e^{o b s}, \kappa^{o b s}\right)+F_{i=1}^{n} I_{i}^{o b s}}
$$

The results are displayed in the third row of Table 7. Using an F-P test, we do not observe a significant difference in overall performance between the different policy instruments. We summarize our result as follows:

Result 4c: Overall, the three policy instruments leads to similar final total efficiency.

\section{Concluding Remarks}

The aim of this study was to investigate by methods of experimental economics whether emission permit markets provide efficient incentives for polluting firms to adopt cleaner technologies. In particular, we have been interested in the performance of different institutional frameworks, notably the choice of the initial allocation of permits (costly vs. free) and the choice of auction design and how these affect investment incentives.

We find that the firms' overall performance with respect to investment under tradable permits is remarkably good, even though, in line with Gangadharan et al (forthcoming), we observe some under-investment by inefficient firms and some overinvestment by less inefficient firms. Moreover, none of the three mechanisms induces allocations closer to the socially optimal investment pattern than any of the other two. We also find that the allocation mechanism (auctioning vs. grandfathering) does not affect the efficiency in permit allocation (for a given technological level). This result supports the theoretical results obtained by Kennedy and Laplante (2000), Requate and Unold (2003, 2001), and Montero (2002a,b), who show that in competitive permit 
markets, the initial allocation of permits does not affect the final allocation of permits and emissions. However, we find a higher variance in the performance when permits are first auctioned off rather than allocated for free. This may indicate that under grandfathering the final permit allocation is closer to the initial allocation of permits. Moreover, we find that the double auction is more efficient in permit allocation than the ascending clock auction. Thus, we deliver a further argument in favor of the celebrated double auction trading institution. Regarding total abatement cost (i.e., abatement and investment costs) we do not find overall differences in performance between the treatments. The result that auctioning is not preferred to grandfathering in any of the efficiency criteria is remarkable in light of most economists' preference of auctioning over grandfathering (see, for instance, Cramton and Kerr, 2002). ${ }^{32}$

In our experimental design we endowed the firms with asymmetric technologies and all firms are relatively small compared to the whole market, and thus have little market power. Montero (2002a,b) has shown that the initial allocation does affect the firms' investment decisions if firms can exercise market power on either the permit or the output market. While for the European $\mathrm{CO}_{2}$ market even the large utilities are relatively small compared to the whole $\mathrm{CO}_{2}$ emission permit market, in other existing permit markets, notably the American $\mathrm{SO}_{2}$ market (see Rico, 1995), large buyers and sellers of permits exist. Further research is therefore needed to cast light on the question whether institutional design matters with respect to investment incentives when firms do exercise market power. In this respect, it may be interesting to draw on the designs reported by Godby et al (1999) and Godby (2000) to investigate the incentives for adopting a low-pollution technology where one or more firm have considerable market power. This case actually implies that permit and product market may no longer be considerd to be separable. Another issue we still know little about is the way in which the degree of asymmetry among firms affects investment efficiency. As stressed by Requate and Unold (2003), complete symmetry may induce a coordination problem with respect to which firms will invest and which 
will not. Strategic uncertainty may induce both over- and under-investment. Even in our experiment with its rather asymmetric firms, strategic uncertainty could not be eliminated completely. This uncertainty increases with greater symmetry among the firms. In the light of the relative paucity of experimental literature in this area, a systematic investigation of this issue is certainly worth pursuing.

\section{Notes}

${ }^{1}$ See Requate (2005) for a survey of incentives provided by environmental policy instruments to adopt and develop advanced abatement technologies.

${ }^{2}$ This assumption comes close to the situation in European countries as a result of the Integrated Pollution Prevention and Control (IPPC) Directive 96/61. The IPPC legislation requires emission reduction and environmental improvements on the basis of what is achievable with the best techniques available to individual industrial sectors.

${ }^{3}$ There are other studies investigating the impact of different auction designs or costly vs. free allocation of permits (for instance, Wråke et al, 2010), but to our knowledge, no other study has yet investigated this impact on technology adoption.

${ }^{4}$ A summary of the literature is given in Muller and Mestelman (1998) and in Bohm (2003).

${ }^{5}$ Dynamic optimality refers to long-term abatement incentives including adoption (and also innovation through $\mathrm{R} \& \mathrm{D}$ ) of new technologies.

${ }^{6}$ We originally had planned to issue $L=110$ permits, which is the optimal emission level with a hypothetical damage function of $D(E)=\frac{E^{2}}{4}$ (as illustrated in Figure 1). To avoid integer problems, we reduced the number of permits to 108 in the case of grandfathering. Since the $A M A C$ curve is a step function, the theoretical competitive equilibrium price for permits is $60 \mathrm{ECU}$ in both cases, and the small difference of 2 permits should not affect the results.

${ }^{7}$ Note that, given the optimal investment pattern, at any price below 60 ECU there is excess demand for emission permits. At a price of $60 \mathrm{ECU}$, firms are indifferent between abating the last unit or holding a permit for the last unit.

${ }^{8}$ See Smith (1962) and Smith and Williams (1992).

${ }^{9}$ We are aware that such uniform price auction might be inefficient since bidders may have an incentive to bid below their demand function in order to keep the clearing prices down. Ausubel (2004) proposes an alternative ascending-clock auction with Vickrey pricing that achieves full efficiency. However, as Cramton and Kerr (2002) state, in the absence of market power the inefficiency 
that results from an ascending clock auction with uniform pricing is likely to be insignificant and it is easier to implement.

${ }^{10}$ Each subject was allowed to participate in only one session.

${ }^{11}$ Instructions are available from the authors upon request.

${ }^{12}$ We have conducted a trial round which was identical to the real rounds (i.e., including both, investment and abatement decisions) except that it was not considered for the payoff beforehand.

${ }^{13}$ We have conducted two trials rounds of the auction (but without the investment decision) beforehand.

${ }^{14}$ If a subject does not submit her demand in time, the computer program automatically submits the subject's demand at the previous price. If the subject does not submit her demand at the initial price (5 ECU), the computer program automatically submits her maximum emission level. However, this hardly ever occurred.

${ }^{15}$ We chose $15,25, \ldots$, instead of $10,20, \ldots$ to avoid ties.

${ }^{16}$ If demand is equal to supply, then each offerer also sells her offered quantity. However, if demand is smaller than supply, a random mechanism determines which of the offerers will sell their offered quantities and which will not.

${ }^{17}$ We were merely interested in measuring differences between subjects regarding their risk attitude and not in the exact functional form of their utilities. Therefore, we have used the number of consecutive low risk choices before switching to the high risk choices as our risk measure.

${ }^{18}$ The F-P test, like the popular Wilcoxon-Mann-Whitney (WMW) test, tests for the difference in medians of two samples. But, unlike the WMW test, it also works well for samples with different variances (see Feletovich, 2003). For the analysis we used the simulated critical values for small samples (Feltovich, 2005).

${ }^{19}$ In particular, averages of $77 \%, 85 \%$, and $80 \%$ of the investment decisions in the AAC, GAC, and GDA treatments, respectively, follow the behavior predicted by the efficient equilibrium.

${ }^{20}$ We used a one-sample sign-rank test.

${ }^{21}$ Using a linear probability model yields similar results.

${ }^{22}$ We omitted the data of two subjects from the AAC, and GAC treatments and one subject from the GDA treatment who did not fill in the risk test. Since the risk attitude measure may be correlated with the error term we made a robustness check by estimating the model presented in Table 3 (and Table 6) with and without the risk attitude measure. Generally, the other coefficients are not affected by the absence of this variable.

${ }^{23}$ The $T_{5}$ coefficient is absent from GAC estimation results presented in Table 3 since we only observe one investment of such firm which was done in the first round (the estimation does not 
include round 1).

${ }^{24}$ In all three sessions of the treatments with grandfathering (GAC and GDA) the average permit price is higher than the expected price. In two of three sessions of the AAC treatment the average permit price is higher than the expected price.

${ }^{25}$ In all three sessions of each treatment the average (net) trading volume is higher than the expected trading volume.

${ }^{26}$ We exclude investment as an explanatory variable from the regression because Table 3 indciates that the initial technology is the main determinant for investment in the GDA treatment.

${ }^{27}$ The average profit per round obtained by those subjects doing speculative (non speculative) trading is $716.80 \mathrm{ECU}$ (770.50 ECU). The result is significant at the $1 \%$ significance level (using an F-P test).

${ }^{28} \mathrm{P}$-value larger than the $10 \%$ significance level using simulated small-sample values.

${ }^{29}$ All three average ratios in the GDA sessions are larger than their counterparts in the GAC treatment.

${ }^{30}$ The significance level is larger than $10 \%$ between each pair of treatments.

${ }^{31}$ Note that the total efficiency cannot simply be written as the product of permit-market efficiency and investment efficiency, the reason being that $E-$ Ratio $^{\text {invest }}$ and $E-$ Ratio $^{\text {total }}$ contain the investment cost while $E-$ Ratio $^{\text {permit }}$ does not. To relate $E-$ Ratio $^{\text {permit }}$ and $E-$ Ratio $^{\text {invest }}$ to $E-$ Ratio $^{\text {total }}$ we had to normalize the product $E-$ Ratio $^{\text {permit }} \times E-$ Ratio $^{\text {invest }}$ by the factor $\frac{{ }_{i=1}^{n} A C_{i}\left(e_{i}^{o b s}, \kappa_{i}^{o b s}\right)}{{ }_{i=1}^{n} A C_{i}\left(e_{i}^{o b s}, \kappa_{i}^{o b s}\right)+{ }_{i=1}^{n} I_{i}^{o b s} F} / \frac{{ }_{i=1}^{n} A C_{i}\left(e_{i}^{*}\left(\kappa^{o b s}\right), \kappa_{i}^{o b s}\right)}{{ }_{i=1} A C_{i}\left(e_{i}^{*}\left(\kappa^{o b s}\right), \kappa_{i}^{o b s}\right)+{ }_{i=1}^{n} I_{i}^{I b s} F}$ the values of which, however, are of no further interest.

${ }^{32}$ There are nevertheless strong reasons to favor auctioning over grandfathering because auction revenues can contribute to lowering the costs of raising public funds that arise elsewhere through distortionary taxes. This effect is known as the 'weak double dividend' (see Goulder, 1995). 


\section{A The Tax Treatment}

Every experimental session started with a tax treatment ("Part I" in the instructions). Only then did it proceed with the auction treatment. The structure of the tax treatment is similar to that of the permit auction treatments, the only difference being that the government imposes a tax per emission that is equal for all firms (instead of participating in an auction). The idea of conducting the tax treatment is to make subjects familiar with the setting (but without the uncertainty involved in the auctions). Also, the tax treatment enables us to evaluate whether the subjects have understood the setting before we proceed with the actual experiment.

Under the assumption that the regulator anticipates the new technology, we set the ex-ante optimal tax rate equal to $\tau=55$. According to the above settings, the profit of firm $i$ in round $t$ is the following:

$$
\Pi_{i, t}= \begin{cases}\Pi^{0}-C^{i}\left(e_{i, t}, a\right)-\tau e_{i, t}-F & \text { if invested in round } t \\ \Pi^{0}-C^{i}\left(e_{i, t}, k\right)-\tau e_{i, t} & \text { if did not invest in round } t\end{cases}
$$

where $k=T_{1}, \ldots, T_{5}$ and $a$ denotes the advanced abatement technology.

Since the tax treatment is basically a maximization problem, non-optimal decisions by the subjects are considered 'errors'. Consequently, we identify two types of errors, (i) a non-optimal abatement decision, i.e., a firm abates more or fewer units than is optimal under the given tax rate and (ii) a non-optimal investment decision, i.e., either a firm invests although it should not, or a firm does not invest although it should. Table A.1 shows the percentage of errors in the first and last rounds of the treatment.

- Table A.1 around here -

Table A.1 illustrates that the percentage of errors is substantially lower in the last 
round in comparison with the first round, implying that at the end of the treatment the subjects have a much better grasp of the economic situation. At the end of the treatment, only about $10 \%$ of the decisions made by the subjects are classified as erroneous in comparison with more than $20 \%$ in the first round.

\section{B Holt and Laury's (2002) Menu of Paired Lottery}

Holt and Laury's (2002) low payoff menu of paired lotteries (see Figure B.1) requires subjects to choose between two lotteries: A and B. The 'safer' lottery A includes a probability of winning a high payoff of $€ 2$ and a (complementary) probability of wining a low payoff of $€ 1.6$. (In the original study by Holt and Laury (2002) the payoffs are in US\$.) Similarly, the 'riskier' lottery B includes a probability of winning a high payoff of $€ 3.85$ and a (complementary) probability of wining a low payoff of $€ 0.1$. The probabilities of wining the high (and low) payoffs are the same for both lotteries. The probability of winning the high payoff gradually increases during the lottery-choice menu in increments of $10 \%$, proceeding from a $10 \%$ probability of winning the high payoff and a $90 \%$ probability of winning the low payoff in the first lottery-choice, to a $100 \%$ probability of winning the high payoff and a $0 \%$ probability of winning the low payoff in the last choice of the menu. As the probability of winning the high payoff in both lotteries increases, subjects are expected to switch from A to $\mathrm{B}$ since the expected value in lottery B increases more than it does in lottery A. For instance, a risk-neutral subject who chooses the lottery according to the highest

expected value will choose A exactly four times before switching to B. Consequently, from the pattern of choices observed, a risk-attitude measure is computed which corresponds to the number of consecutive choices in lottery A before switching to lottery B.

- Figure B.1 around here - 


\section{References}

Ausubel LM (2004) An efficient ascending-bid auction for multiple objects. American Economic Review 94(5):1452-1475

Ben-David S, Brookshire DS, Burness S, McKee M, Schmidt C (1999) Heterogeneity, irreversible production choices, and efficiency in emission permit markets. Journal of Environmental Economics and Management 38:176-194

Bohm P (2003) Experimental evaluations of policy instruments. In: Mäler KG, Vincent JR (eds) Handbook of Environmental Economics, Vol. 1, Elsevier, pp 437-460

Botelho A, Fernandes E, Pinto LC (2011) An experimental analysis of grandfathering versus dynamic auctioning in the EU ETS. In: Isaac RM, Norton DA (eds) Experiments on Energy, the Environment, and Sustainability (Research in Experimental Economics, Volume 14), Emerald Group Publishing Limited, pp 37-76

Buckley NJ, Muller RA, Mestelman S (2005) Baseline-and-credit style emission trading mechanisms: An experimental investigation of economic inefficiency. Department of Economics Working Papers 2005-04, McMaster University

Buckley NJ, Mestelman S, Muller RA (2006) Implications of alternative emission trading plans: Experimental evidence. Pacific Economic Review 11:149-166

Cramton P, Kerr S (2002) Tradeable carbon permit auctions: How and why to auction not grandfather. Energy Policy 30:333-345

Downing PB, White LJ (1986) Innovation in pollution control. Journal of Environmental Economics and Management 13:18-29

Feletovich N (2003) Nonparametric tests of differences in medians: Comparison of the Wilcoxon-Mann-Whitney and Robust Rank-Order tests. Experimental Economics 6:273-297 
Feltovich N (2005) Critical values for the robust rank-order test. Communications in Statistics - Simulation and Computation 34:525-547

Fischbacher U (2007) z-Tree: Zurich toolbox for ready-made economic experiments. Experimental Economics 10:171-178

Fischer C, Parry IWH, Pizer WA (2003) Instrument choice for environmental protection when technological innovation is endogenous. Journal of Environmental Economics and Management 45:523-545

Fligner MA, Policello GE (1981) Robust rank procedures for the Behrens-Fisher problem. Journal of the American Statistical Association 76:162-168

Gangadharan L, Farrell A, Croson R (forthcoming) Investment decisions and emissions reductions: Results from experiments in emissions trading. In: List JA, Price M (eds) Handbook on Experimental Economics and the Environment, Edward Elgar Publishing Ltd., Cheltenham, UK and Northampton, MA

Godby R (2000) Market power and emission trading: Theory and laboratory results. Pacific Economic Review 5:349-363

Godby R, Mestelman S, Muller RA (1999) Experimental tests of market power in emission trading markets. In: Petrakis E, Sartzetakis E, Xepapadeas A (eds) Environmental Regulation and Market Power: Competition, Time Consistency and International Trade, Edward Elgar Publishing Ltd., Cheltenham, United Kingdom, pp 67-94

Goeree JK, Holt CA, Palmer K, Shobe W, Burtraw D (2010) An experimental study of auctions versus grandfathering to assign pollution permits. Journal of the European Economic Association 8:514-525

Goulder LH (1995) Environmental taxation and the 'double dividend': A reader's guide. International Tax and Public Finance 2:157-183 
Hizen Y, Kusakawa T, Niizawa H, Saijo T (2001) Two patterns of price dynamics were observed in greenhouse gases emissions trading experiments: An application of point equilibrium. Working paper, Institute of Social and Economic Research, Osaka University

Holt CA, Laury SK (2002) Risk aversion and incentive effects. American Economic Review 92:1644-1655

Jung C, Krutilla K, Boyd R (1996) Incentives for advanced pollution abatement technology at the industry level: An evaluation of policy alternatives. Journal of Environmental Economics and Management 30:95 111

Kennedy PW, Laplante B (2000) Environmental policy and time consistency: Emissions taxes and emissions tradings. In: Petrakis E, Sartzetakis ES, Xepapadeas A (eds) Environmental Regulation and Market Power, Edward Elgar Publishing inc., Hants, England, pp 116-144

Kneese AV, Schultze CL (1975) Pollution, Prices and Public Policy. Brokings, Washington, D.C.

Kusakawa T, Saijo T (2003) Emissions trading experiments: Investment uncertainty reduces market efficiency. In: Sawa T (ed) International Frameworks and Technological Strategies to Prevent Climate Change, Springer-Verlag, New York, pp $45-65$

Ledyard JO, Szakaly-Moore K (1994) Designing organizations for trading pollution rights. Journal of Economic Behavior and Organization 25:167-196

Loewenstein G (1999) Experimental economics from the vantage-point of behavioural economics. Economic Journal 109:F23-34

Malueg DA (1989) Emission credit trading and the incentive to adopt new pollu- 
tion abatement technology. Journal of Environmental Economics and Management $18: 52-57$

Milliman SR, Prince R (1989) Firms incentives to promote technological change in pollution control. Journal of Environmental Economics and Management 17:247265

Montero JP (2002a) Market structure and environmental innovation. Journal of Applied Economics 5:293-325

Montero JP (2002b) Permits, standards, and technology innovation. Journal of Environmental Economics and Management 44:23-44

Muller RA, Mestelman S (1998) What have we learned from emissions trading experiments? Managerial and Decision Economics 19:225-238

Plott CR (1983) Externalities and corrective policies in experimental markets. The Economic Journal 93:106-127

Requate T (2005) Dynamic incentives by environmental policy instruments - a survey. Ecological Economics 54:175-195

Requate T, Unold W (2001) On the incentives created by policy instruments to adopt advanced abatement technology if firms are asymmetric. Journal of Institutional and Theoretical Economics 157:536-554

Requate T, Unold W (2003) Environmental policy incentives to adopt advanced abatement technology: Will the true ranking please stand up? European Economic Review 47:125-146

Rico R (1995) The U.S. allowance trading system for sulfur dioxide: An update on market experience. Environmental and Resource Economics 5:115-129

Smith VL (1962) An experimental study of competitive market behavior. Journal of Political Economy 70:111-137 
Smith VL (1986) Experimental methods in the political economy of exchange. Science 234:167-173

Smith VL, Williams AW (1992) Experimental market economics. Scientific American $267: 116-122$

Smith VL, Suchanek GL, Williams AW (1988) Bubbles, crashes, and endogenous expectations in experimental spot asset markets. Econometrica 56:1119-51

Wråke M, Myers EC, Burtraw D, Mandell S, Holt C (2010) Opportunity cost for free allocations of emissions permits: An experimental analysis. Environmental and Resource Economics 46:331-336 


\begin{tabular}{c|cccccc}
\hline \hline \multirow{2}{*}{ MAC } & \multicolumn{6}{|c}{ Emissions $\left(e_{i}\right)$ per technology type } \\
\cline { 2 - 7 } & $T_{1}$ & $T_{2}$ & $T_{3}$ & $T_{4}$ & $T_{5}$ & $a$ \\
\hline \hline 0 & 20 & 18 & 16 & 14 & 12 & 7 \\
10 & 19 & 17 & 15 & 13 & 11 & 6 \\
20 & 18 & 16 & 14 & 12 & 10 & 5 \\
30 & 17 & 15 & 13 & 11 & 9 & 4 \\
40 & 16 & 14 & 12 & 10 & 8 & 3 \\
50 & 15 & 13 & 11 & 9 & 7 & 2 \\
60 & 14 & 12 & 10 & 8 & 6 & 1 \\
70 & 13 & 11 & 9 & 7 & 5 & 0 \\
80 & 12 & 10 & 8 & 6 & 4 & 0 \\
90 & 11 & 9 & 7 & 5 & 3 & 0 \\
100 & 10 & 8 & 6 & 4 & 2 & 0 \\
110 & 9 & 7 & 5 & 3 & 1 & 0 \\
120 & 8 & 6 & 4 & 2 & 0 & 0 \\
130 & 7 & 5 & 3 & 1 & 0 & 0 \\
140 & 6 & 4 & 2 & 0 & 0 & 0 \\
150 & 5 & 3 & 1 & 0 & 0 & 0 \\
160 & 4 & 2 & 0 & 0 & 0 & 0 \\
170 & 3 & 1 & 0 & 0 & 0 & 0 \\
180 & 2 & 0 & 0 & 0 & 0 & 0 \\
190 & 1 & 0 & 0 & 0 & 0 & 0 \\
200 & 0 & 0 & 0 & 0 & 0 & 0 \\
\hline \hline
\end{tabular}

Table 1: Marginal Abatement Cost (MAC) per technology type. $T_{1}, \ldots, T_{5}$ denote the initial technologies, while $a$ denotes the advanced abatement technology.

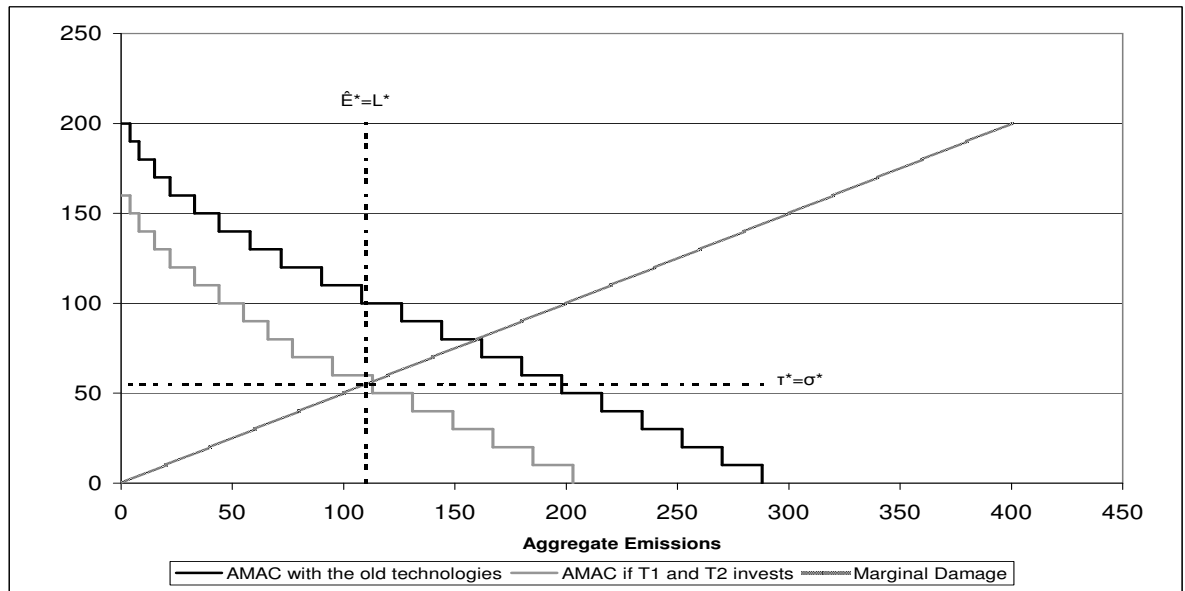

Figure 1: Socially optimal instrument level, tax and emission permits.

\begin{tabular}{lccccc}
\hline \hline Firm type & $T_{1}$ & $T_{2}$ & $T_{3}$ & $T_{4}$ & $T_{5}$ \\
Number of firms & 4 & 3 & 4 & 3 & 4 \\
Permits allocated & 8 & 7 & 6 & 5 & 4 \\
\hline \hline
\end{tabular}

Table 2: Firm type (according to the initial technologies), number of firms per type, and number of permits allocated to each firm in the treatments with grandfathering. 


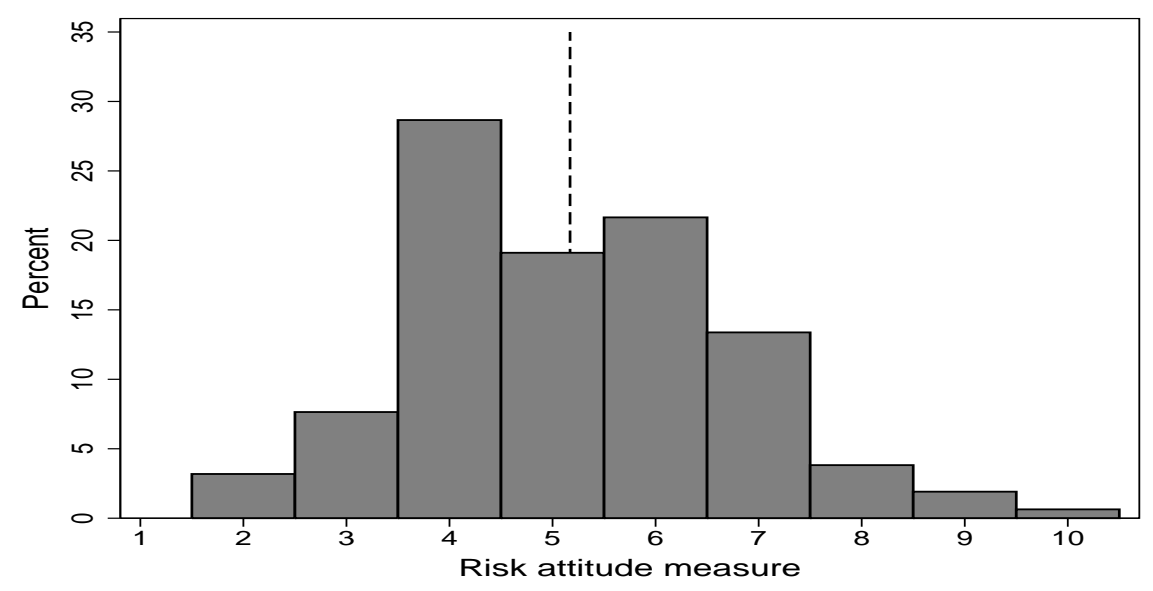

Figure 2: The distribution of the risk-attitude measures (average: 5.17, standard deviation: 1.55). Measure in the range 1-3 indicate risk loving, a measure of 4 indicates risk neutrality, and measure in the range 5-10 indicate risk aversion.

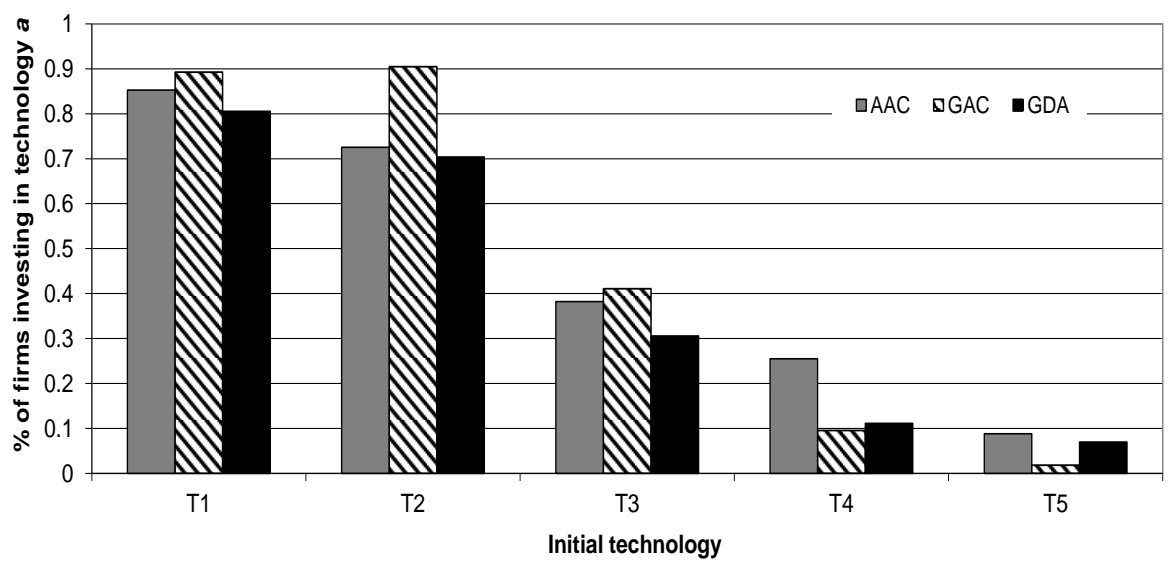

Figure 3: Percentage of firms investing in technology $a$ per initial Technology $k=$ $T_{1}, \ldots, T_{5}$. 


\begin{tabular}{lccc}
\hline \hline Treatment & AAC & GAC & GDA \\
\hline \hline Technology $T_{2}(t)$ & -0.466 & 0.153 & -0.283 \\
& $(0.375)$ & $(0.238)$ & $(0.308)$ \\
Technology $T_{3}(t)$ & $-0.994^{* * *}$ & $-1.486^{* * *}$ & $-1.517^{* * *}$ \\
& $(0.070)$ & $(0.305)$ & $(0.353)$ \\
Technology $T_{4}(t)$ & $-1.504^{* * *}$ & $-2.685^{* * *}$ & $-2.100^{* * *}$ \\
& $(0.166)$ & $(0.510)$ & $(0.384)$ \\
Technology $T_{5}(t)$ & $-2.165^{* * *}$ & - & $-2.860^{* * *}$ \\
& $(0.068)$ & & $(0.334)$ \\
Risk-attitude measure & 0.011 & $-0.094^{* *}$ & 0.141 \\
Average price $(t-1)$ & $(0.070)$ & $(0.040)$ & $(0.093)$ \\
& $0.008^{*}$ & 0.008 & 0.012 \\
Round & $(0.005)$ & $(0.017)$ & $(0.008)$ \\
& -0.187 & -0.152 & 0.010 \\
Cons & $(0.149)$ & $(0.093)$ & $(0.058)$ \\
& 1.159 & 1.915 & -0.640 \\
\hline Pseudo- $R^{2}$ & $(1.333)$ & $(1.761)$ & $(0.988)$ \\
\hline \hline
\end{tabular}

Table 3: Pooled Probit estimation (with clustered standard error across sessions) of the different treatments (std. err. are given in parentheses). The dependent variable: investment in round $t .{ }^{* * *},{ }^{* *}$, and ${ }^{*}$ denote significance at the $1 \%$ or lower level, between $1 \%$ and $5 \%$, and between $10 \%$ and $5 \%$ levels, respectively.

\begin{tabular}{lcccc}
\hline \multirow{2}{*}{ Treatment } & \multicolumn{2}{c}{ Observed } & \multicolumn{2}{c}{ Expected } \\
\cline { 2 - 5 } & Price & Volume & Price & Volume \\
\hline \hline AAC & 53.55 & 102.86 & 54.00 & 110 \\
& $(5.73)$ & $(4.10)$ & $(1.73)$ & $(-)$ \\
GAC & 58.88 & 32.58 & 52.77 & 37.33 \\
& $(3.15)$ & $(1.01)$ & $(2.54)$ & $(1.04)$ \\
GDA & 66.47 & 43.44 & 60.55 & 36.77 \\
& $(6.52)$ & $(6.94)$ & $(4.19)$ & $(1.22)$ \\
\hline \hline
\end{tabular}

Table 4: Mean observed and expected prices and trade volumes of permits (SD are given within parentheses). The reported prices and volumes are averaged across sessions and rounds within a given treatment.

\begin{tabular}{cccc}
\hline \hline \multirow{2}{*}{ Treatment } & \multicolumn{2}{c}{ Observed volume } & Expected volume \\
\cline { 2 - 3 } & Net & Total & \\
\hline \hline \multirow{2}{*}{ GDA } & 31.50 & 43.44 & 36.77 \\
& $(6.43)$ & $(6.94)$ & $(1.22)$ \\
\hline \hline
\end{tabular}

Table 5: Mean (std. dev.) of observed net trading in comparison with total trading in the GDA treatment. 


\begin{tabular}{ll}
\hline \hline Variable & Coef. (Std. Err.) \\
\hline \hline Technology $T_{2}(t)$ & -0.251 \\
& $(0.317)$ \\
Technology $T_{3}(t)$ & -0.047 \\
& $(0.461)$ \\
Technology $T_{4}(t)$ & 0.027 \\
& $(0.306)$ \\
Technology $T_{5}(t)$ & -0.025 \\
& $(0.441)$ \\
Risk-attitude measure & $-0.175^{* * *}$ \\
& $(0.033)$ \\
Average price $(t-1)$ & $0.019 * *$ \\
& $(0.008)$ \\
Round & -0.058 \\
Cons & $(0.043)$ \\
& -0.584 \\
Pseudo- $R^{2}$ & $(0.378)$ \\
\hline \hline
\end{tabular}

Table 6: pooled probit estimation of the GDA treatment (with clustered standard error across sessions). The dependent variable: speculation in round $t$ (std. err. are given in parentheses). ${ }^{* * *}$, and ${ }^{* *}$ denote significance at the $1 \%$ or lower level, and between $1 \%$ and $5 \%$ levels, respectively.

\begin{tabular}{|c|c|c|c|}
\hline & $\mathrm{AAC}$ & GAC & GDA \\
\hline$E R^{\text {Permit }}$ & $\begin{array}{c}0.76 \\
(0.11)\end{array}$ & $\begin{array}{c}0.79 \\
(0.00)\end{array}$ & $\begin{array}{c}0.83 \\
(0.02)\end{array}$ \\
\hline$E R^{\text {Invest }}$ & $\begin{array}{c}0.92 \\
(0.04)\end{array}$ & $\begin{array}{c}0.93 \\
(0.00)\end{array}$ & $\begin{array}{c}0.92 \\
(0.01)\end{array}$ \\
\hline$E R^{\text {Total }}$ & $\begin{array}{c}0.83 \\
(0.09)\end{array}$ & $\begin{array}{c}0.86 \\
(0.01)\end{array}$ & $\begin{array}{c}0.85 \\
(0.01)\end{array}$ \\
\hline
\end{tabular}

Table 7: Mean (Std. Dev.) of the different efficiency ratios.

\begin{tabular}{ccc}
\hline \hline & $\%$ of investment errors & $\%$ of abatement errors \\
\hline \hline First round & 21.66 & 26.45 \\
Last round & 9.80 & 10.54 \\
\hline \hline
\end{tabular}

Table A.1: Percentage of errors in the first and the last rounds of the tax treatments (a total of 162 subjects). 


\begin{tabular}{|c|c|c|c|}
\hline Number & Option A & Option B & $\begin{array}{l}\text { Your } \\
\text { Decision } \\
\text { (A or B) }\end{array}$ \\
\hline 1 & $1 / 10$ of $€ 2.00,9 / 10$ of $€ 1.60$ & $1 / 10$ of $€ 3.85,9 / 10$ of $€ 0.10$ & \\
\hline 2 & $2 / 10$ of $€ 2.00,8 / 10$ of $€ 1.60$ & $2 / 10$ of $€ 3.85,8 / 10$ of $€ 0.10$ & \\
\hline 3 & $3 / 10$ of $€ 2.00,7 / 10$ of $€ 1.60$ & $3 / 10$ of $€ 3.85,7 / 10$ of $€ 0.10$ & \\
\hline 4 & $4 / 10$ of $€ 2.00,6 / 10$ of $€ 1.60$ & $4 / 10$ of $€ 3.85,6 / 10$ of $€ 0.10$ & \\
\hline 5 & $5 / 10$ of $€ 2.00,5 / 10$ of $€ 1.60$ & $5 / 10$ of $€ 3.85,5 / 10$ of $€ 0.10$ & \\
\hline 6 & $6 / 10$ of $€ 2.00,4 / 10$ of $€ 1.60$ & $6 / 10$ of $€ 3.85,4 / 10$ of $€ 0.10$ & \\
\hline 7 & $7 / 10$ of $€ 2.00,3 / 10$ of $€ 1.60$ & $7 / 10$ of $€ 3.85,3 / 10$ of $€ 0.10$ & \\
\hline 8 & $8 / 10$ of $€ 2.00,2 / 10$ of $€ 1.60$ & $8 / 10$ of $€ 3.85,2 / 10$ of $€ 0.10$ & \\
\hline 9 & $9 / 10$ of $€ 2.00,1 / 10$ of $€ 1.60$ & $9 / 10$ of $€ 3.85,1 / 10$ of $€ 0.10$ & \\
\hline 10 & $10 / 10$ of $€ 2.00,0 / 10$ of $€ 1.60$ & $10 / 10$ of $€ 3.85,0 / 10$ of $€ 0.10$ & \\
\hline
\end{tabular}

Figure B.1: Holt and Laury's (2002) menu of paired lottery 